\title{
ENERGY BASED FOOD SECURITY ASSESSMENT IN NEPAL
}

\author{
Surya P. Paudel ${ }^{1}$ and Sabnam Shivakoti MSc ${ }^{* 2}$
}

\begin{abstract}
The basis of total edible cereal production of the district, the total population and the food requirement (Kcal/person/year) has been the basis for delineating food insecure districts. Many interventions of food security and food aid programs are mostly directed to those districts on this basis. The major objective of this paper is to assess the food security from energy production point of view considering the total energy from cereals, potato, vegetables, milk and meat. The data is based on the publication of MOAC. It was found that Nepal is sufficient in terms of energy adequacy although the situation for Terai, Hills and Mountain are different. Terai, known for its food basket, was not found better than hills in terms of food energy production required for their districts. Although Nepal has been energy adequate, the prevalence of chronic malnutrition shows the need for different intervention. In addition, Nepal suffers from protein energy malnutrition (PEM), which clearly indicates the need for crop diversification. Current food-security assessment methodology needs to be revisited and redefined.
\end{abstract}

Key Words: food security, assessment, energy production, energy adequacy, malnutrition

\section{INTRODUCTION}

Whether viewed globally at the nation level or in local communities, food security has been recognized as an essential, universal dimension of household and personal well-being. Therefore, the deprivation of basic need represented by food insecurity and hunger are undesirable in their own right and often viewed as possible precursors to nutritional, health, and developmental problems (Bickle, 2000).

Monitoring food security can help to identify and understand this basic aspect of well being of the population and to identify population subgroups or regions with unusually severe conditions (Bickle, 2000). Ensuring food security is a complex phenomenon and its assessment and monitoring is equally challenging yet very important. Use of appropriate system to assess food security from its all dimensions (food availability, access, utilization and stability) enables us to articulate appropriate interventions and policy to address the problems on appropriate time (Shivakoti and Paudel, 2011). However, currently food and nutrition security monitorings in Nepal are done in isolation, and often inadequate.

While the food balance of Nepal is based on edible production of major five cereals viz paddy, wheat, maize, barley and millet, there is often low relation between food deficit districts and the districts with high number of malnourishment. For example, most of the Terai districts are food sufficient from the current assessment methods while malnourishment has also been prone in these areas. This needs further deeper analysis.

Despite the fact that each and every dimensions of food security are more or less equally important, food availability still can be considered as the first and foremost important element to enhance the situation of food and nutrition security, especially in a country like Nepal. Therefore, this paper basically tries to analyze the 'availability' dimension of food security in terms of total energy production from various food sources in the districts.

\footnotetext{
${ }^{1}$ Senior Livestock Dev. Officer, Ministry of Agriculture and Cooperatives, Kathmandu

2 Senior Agriculturist, Ministry of Agriculture and Cooperatives, Kathmandu
} 


\section{METHODOLOGY}

This paper is based on the secondary data published by Ministry of Agriculture and Cooperatives. The data analysis has been done for various crops and livestock production of District Agriculture Development Offices (DADO) and District Livestock Services Offices (DLSO) production statistics during 2010 and the compiled data for the region and is basically analyzed in terms of energy production.

With growth in incomes, food consumption patterns have changed towards high value items like livestock and fishery products, fruits and vegetables, across income quintiles. The largest jumps have been found in the livestock sector, especially poultry and fish consumption which have gone up by $100 \%$ and $47 \%$, although from a very low base, and in potatoes the consumption has increased by over 30\% between 1995/96 and 2003/04 (IFPRI, 2010). Therefore, for the analysis purpose, the energy calculation has been done for the cereals (paddy, wheat, maize, millet and barley), vegetables (grouped into summer and winter vegetables), potato, milk and meat. Each district has been considered as a unit for analysis.

\section{LIMITATIONS OF THE STUDY}

This analysis has not considered the energy production from pulses, fruits and fisheries, largely because pulses and fruits have are relatively low energy dense food, fisheries being concentrated in selective regions. The energy availability from imports and food aids have not been accounted and only the local production has been considered.

Similarly, the energy requirement for a people depends on the age, type of work, sex and place where they live. However, the effect of age, sex and place were disregarded in this study.

Energy requirement per person per day for Nepal was recommended as $1760 \mathrm{kcal}$ by a recent study conducted(IFPRI, 2010) and this has been used in this study as the energy requirement per person per day irrespective of age, sex, place and their life style.

\section{METHODS OF ANALYSIS}

The analyses have been focused on the contributions of major sub-sectors of agriculture to food security in supplying calorie to the people. Energy availability and energy consumption per capita was taken as an indicator to assess the status of the food security. First of all, energy production from each of these ten commodities was estimated with the following equation and added to get the district level energy production.

$e p=(T P-P H L) x E C x E D$ where,

ep $=$ Energy production from a commodity in a district

$\mathrm{TP}=$ total production of a crop/commodity

$\mathrm{PHL}=$ Post harvest loss including amount used for seed for next crop cycle, amount not used for human food,

$E C=$ Coefficient for edible part of a commodity

$E D=$ Energy density in a commodity expressed as Kcal per kg of edible amount of the commodity

The total energy production of the ten commodities (five cereals, potato, summer and winter vegetables, milk and meat) in each district was estimated using the following equation: $E P=\sum C_{i} L_{j} V_{k}$ where,

$\mathrm{EP}=$ Food energy production in a district from net edible production of $\mathrm{Ci}$ crops, $\mathrm{Lj}$ livestock products and Vk vegetable

$\mathrm{C} i=$ energy production from $i$ th crops where $\mathrm{i}=1$ to 6 (paddy, maize, millet, wheat, barley and potato) 


$$
\begin{aligned}
& L j=\text { Energy production from Jth livestock products, } j=1 \text { to } 2 \text { (milk and meat) } \\
& V k=\text { Energy production from kth vegetable, } K=1 \text { to } 2 \text { (summer and winter vegetable) }
\end{aligned}
$$

Once the energy production in the district was estimated, it would be imperative to assess whether the energy production was sufficient to feed the population of the districts. Energy adequacy was used to assess the situation of food security of a district using following equation.

$$
\begin{aligned}
E A= & \frac{[\{(\mathrm{TP}-\mathrm{PHL}) \times \mathrm{EC}\} \times \mathrm{ED}\}]}{(\mathrm{P} \times \mathrm{ER} \times \mathrm{D})} \times 100 \\
& \mathrm{EA}=\text { Energy adequacy percentage } \\
\mathrm{TP} & =\text { Total Production } \\
\mathrm{PHL} & =\text { Post Harvest Loss } 1 \\
\mathrm{EC} & =\text { Edible coefficient }
\end{aligned}
$$

$$
\begin{aligned}
& \text { Where, } \\
& \text { ED = Energy Density } \\
& P=\text { Population of district } \\
& E R=\text { Energy requirement } \\
& D=\text { Number of days ( } 365 \text { days) }
\end{aligned}
$$

\section{RESULTS AND DISCUSSIONS}

\section{ENERGY PRODUCTION}

Total food energy production from nine major agricultural commodities is shown in table 1. Total energy production was $1.87 \times 10^{13} \mathrm{Kcal}$ in 2010 from the selected commodities. Rice is the principal commodity for energy production, which contributes almost $40 \%$ of

Table 1: Total food energy production from ten major agricultural commodities in Nepal in 2010.

\begin{tabular}{lll}
\hline & $\begin{array}{l}\text { Eenergy production } \\
(\text { Kcal)/year }\end{array}$ & $\begin{array}{l}\% \text { of the total } \\
\text { energy production }\end{array}$ \\
\hline Rice & $7.54 \times 10^{12}$ & 40.27 \\
Wheat & $4.34 \times 10^{12}$ & 23.20 \\
Maize & $4.36 \times 10^{12}$ & 23.28 \\
Millet & $7.78 \times 10^{11}$ & 4.16 \\
Barley & $2.52 \times 10^{10}$ & 0.14 \\
Potato & $2.07 \times 10^{10}$ & 0.01 \\
Winter vegetable & $1.89 \times 10^{9}$ & 0.01 \\
Summer vegetable & $6.08 \times 10^{8}$ & 0.003 \\
Milk & $1.46 \times 10^{12}$ & 7.80 \\
Meat & $2.15 \times 10^{11}$ & 1.15 \\
Total & $1.87 \times 10^{13}$ & 100 \\
\hline
\end{tabular}

Note: Computed by authors from data compiled by MOAC (2010) and energy concentration given by DFTQC (2061). total food energy production in Nepal in 2010. Rice, wheat and maize are three crops that produced more than $85 \%$ of the total energy production. Although vegetable and livestock products (milk and meat) are not known as the energy dense foods items but are essential elements of the human diet which supplies vitamins and minerals. Milk is principal livestock food items, which alone has contributed $7.8 \%$ of total food energy production of the country.

\section{ENERGY ADEQUACY}

Energy adequacy of Nepal is given in Table 2. Energy adequacy was used as an index to assess whether the energy production from ten major agricultural commodities within a district is able to meet the calorie requirement for the population of that particular district. In 2010, the agricultural production of Nepal was able to feed its entire population from these ten major commodities, in terms of calorie requirement. The overall energy adequacy was almost 104 percent. Considering the contribution of these ten commodities in food energy supply, Nepal is potentially producing sufficient energy for the entire population of the country.

\footnotetext{
${ }^{1}$ The post harvest loss of the crops and livestock products varies from 5 to 25 percent in Nepalese condition.
} 
However, due to unequal distribution of energy among the regions and within the households in each region, the prevalence of undernourished people, underweight children and wasting children in Nepal were 41, 39 and 49 percent. Underweight among pre-school children is highest in Central Terai, while chronic malnutrition (stunting) was highest in Far Western Mountain and Mid Western Hills and acute malnutrition (wasting) was highest among Central and Far Western Terai (NDHS, 2006). Chronic malnutrition is responsible for poor nutritional outcome. Poor nutritional outcome thus requires intervention in the area of increasing economic accessibility and through the intervention in utilization aspects together with safe drinking water, hygiene and sanitation.

Table 2: Energy adequacy (\%) in three ecological region of Nepal in 2010

\begin{tabular}{lccc}
\hline Region & Mean & $\begin{array}{c}\text { Number of } \\
\text { districts }\end{array}$ & $\begin{array}{c}\text { Standard } \\
\text { Deviation (DV) }\end{array}$ \\
\hline Nepal & 103.90 & 75 & 41.74 \\
Hills & 114.82 & 39 & 42.37 \\
Mountain & 75.86 & 16 & 37.01 \\
Terai & 109.75 & 20 & 23.73
\end{tabular}

On the other hand, the contribution of vegetable and livestock products in energy supply is extremely low (less than $10 \%)$. It indicates that the poor nutritional outcome could be the consequence of low intake of vegetable and livestock products like milk and meat. The highest energy adequacy was

found in hills $(114.82 \%)$ and lowest in the mountainous regions $(75.86 \%)$. The reasons for the low energy adequacy in mountainous regions include low productivity of crops used in the analysis. The situation for mountain would be different if we consider the high yielding crops such as fruits in the assessment.

\section{INTRA REGIONAL FOOD ADEQUACY}

Despite the fact that Terai region of Nepal known as the food basket of the country, due to its relatively fertile soil, greater access to technology, inputs and services and greater productivity, it has been producing the adequate food energy $(109.75 \%)$ for its population, but with meager surplus $(9.75 \%)$. Interestingly, districts from hill region are producing sufficient food energy for their people with surplus higher(14.82\%) than Terai $(9.75 \%)$. The surplus energy production of Terai was not better than that of hills.

If we go further down at district levels, 41 districts of the country were found food deficit in terms of total production of cereals while only 33 districts out of 75 districts were not producing sufficient food energy from these ten commodities to meet the food energy requirement for their population. Out of these 33 districts, 8 districts from terai, 12 districts from mountain and 13 districts from hill regions are food energy deficit.

The regions for food deficit could not only be related to the food production but also to the corresponding population of the districts, and level of urbanization. High population growth of district either from birth or from migration and high rate of urbanization limits the strength of the agricultural potentialities of districts to feed its population. Out of total districts in eastern and central development regions, 8 districts were found food energy deficit. They were Mahottari, Siraha, Rautahat, Sarlahi, Sunsari, Chitwan, Saptari and Dhanusha. Mahottari district was far behind among the terai districts to produce enough food for its people (67\% energy adequacy).

\section{CONCLUSIONS AND RECOMMENDATIONS}

The current system of food security assessment, which is based on cereal based food production, is not adequate. The appropriate method may include the per capita energy requirement and energy production or energy availability in a region, such that the energy availability from different sources of foods (including the fishery, fruits and pulses) that are being produced in the district have to be considered. 
Similarly, the current 'Nepal Food Security Monitoring Framework' (NekSAP, 2010) that the government has recently adopted, needs further expansion including the assessment of production and stock of above food source in the indicators.

Although the total energy adequacy is found sufficient but the energy concentration during particular season may affect the food security situation. Therefore, further analyses on energy distribution throughout the year are recommended. The population structure could also give different picture.

Since nutritional outcome is important, the current monitoring system that is being implemented by different agencies in isolation needs integration.

Nutrition outcomes not only reflects calorie consumption, but also a set of absorption and utilization factors such as access to quality healthcare, water supply and sanitation, educational attainment that enable households to take right food and nutritional decisions as well as food safety laws and practices (IFPRI, 2010). Therefore, integrated and multisectoral approach is needed not only in understanding the concept, in setting priorities and action but also in the assessment method.

Appropriate methods to assess food security at household level need to be designed so that most vulnerable households can be identified. A further in depth assessment of food insecurity to identify critical time along with coping strategies guide the planner to design program and projects.

\section{REFERENCES}

Bickel, G., M. Nord, C. Price, W. Hamilton and J. Cook, 2000. Measuring food security in the United States: guide to measuring household food security. United States Department of Agriculture.

DFTQC, 2061. Nepali khadya padarthama paine poshak tatwoharu (in Nepali). Department of Food Technology and Quality Control, National Nutrition Program, Ministry of Agriculture and Cooperatives, Singh durbar, Kathmandu, Nepal.

IFPRI, 2010. Ensuring food and nutritional security in Nepal: A stocktaking exercise. International Food Policy Research Institute for USAID, Kathmandu.

MOAC, 2010. Statistical Information of Nepalese Agriculture. Ministry of Agriculture and Cooperatives (MOAC), Kathmandu, Nepal.

NDHS, 2006. Nepal Demographic and Health Survey 2006. Ministry of Health and Population, New ERA, and Macro International Inc. Kathmandu, Nepal.

NeKSAP, 2010. Nepal food security monitoring system framework document. Govenrment of Nepal, World Food Program and Food and Agriculture Organization, Nepal.

Shivakoti, S. and S. P. Paudel, 2011. Food and ntrition security in Nepal: dimension, issues and challenges. Agriculture Development Journal, vol.8. 